\title{
Organizational Culture for Cooperation in Technological Innovation Between Research Institutes and Firms
}

\author{
Sonia Regina Parolin ${ }^{1 *}$, Leandro Rodrigo Canto Bonfim ${ }^{2}$, Andrea Paula Segatto ${ }^{2}$, Tatiane Espindola ${ }^{3}$
}

\begin{abstract}
This article aims to construct and validate an instrument for measuring the factors of organizational culture that influence cooperation in technological innovation between research institutes and firms, nominated "Evaluation of Organizational Culture for Cooperation in Technological Innovation (EOC-CTI)", applied to the reality of Brazilian organizations. The sample was composed of 324 respondents from 58 large and medium firms and 41 public and private research institutes, from various locations in Brazil. The method adopted was the Exploratory Factor Analysis. Among the main contributions, an instrument that expands the discussions about the values and management practices for cooperation in technological innovation based on organizational culture is proposed. For firms and research institutes, there is the proposition of values and systematic management practices that contribute to the achievement of results through cooperation in technological innovation.
\end{abstract}

Keywords: organizational culture for technological innovation; technological innovation management; technological innovation cooperation; R\&D cooperation; measuring instrument.

Submitted: June $1^{\text {st }}, 2020 /$ Approved: August $25^{\text {th }}, 2020$

\section{Introduction}

Studies on the factors of organizational culture that underlie the effective management processes and routines for cooperation in research and development for technological innovation (RD\&I) are still scant in the literature and the expansion of the concept of cooperation is still very broad, encompassing analyzes of the set of infrastructure and organizational capabilities (Laursen \& Salter, 2006; Wikhamn \& Styhere, 2017).

However, due to the same scope, these concepts receive questions about how to implement, manage effective routines, improve performance and encourage cooperation between organizations, especially in research and development (Feller, Parhankangas, Smeds \& Jaatinen, 2013; Van Beers \& Zand, 2013).

If, on the one hand, there is the increasing environmental complexity and speed of technological change (Hecker, 2016; Van Beers \& Zand, 2013), on the other hand, there is the exponential growth of cooperation in RD\&I, which poses challenges such as measuring the results and performance of cooperation (Degtyarova, Tokareva, Shalina \& Fedorenko, 2016). Likewise, it is important to understand the influence of organizational culture in management practices for obtaining competitive advantages through cooperation in technological innovation (Brettel \& Cleven, 2011; Dobni, 2008; Peeters Massini \& Lewin, 2014). In Claver, Llopis, Garcia and Molina (1998, p. 64) words, "the 'hardware' of technological innovation requires the 'software' of a corporate culture which is aimed at such innovation".

The scientific community points, in general, to the intensification of cooperation under different approaches, such as: incubators, productive arrangements, sectorial and business studies, promotion and subvention, innovation networks, public policies, university-company interaction and technology transfer (Alves, Segatto \& De-Carli, 2016; Tidd, Bessant \& Pavitt, 2008). In these studies it is possible to perceive the voids that needed to be addressed for expanding the approaches to include the influence of the organizational culture in the management processes for cooperation in technological innovation, as organizational efforts resulting from previous strategic dispositions focused on innovation (Claver et al., 1998).

In this regard, this article intends to contribute to the development and validation of an instrument for measuring the factors of organizational culture that influence cooperation in technological innovation between firms and research institutes (public and private), based on associations between two dimensions of analysis: "Values of Culture for Cooperation in Technological Innovation" (independent variables) and "Management for Cooperation in Technological Innovation" (dependent variables). These dimensions and its respective variables were adopted with reference to the Claver's et al. (1998) "culture for technological innovation" model. However, it was expanded from theoretical articulations to actual instruments that contemplate aspects of organizational culture and of management that influence cooperation and technological innovation.

In the next section, the research's methodological procedures are presented, followed by the construction of the theoretical model, the instrument validation process and, finally, the discussions and some considerations about the research, the limitations, the theoretical and practical implications, as well as the proposition of the analysis model denominated in this article as "Evaluation of Organizational Culture for Cooperation in Technological Innovation (EOC-CTI)", applied to the reality of Brazilian organizations.

(1) EGITS - Studies in Management of Innovation, Technology and Sustainability, Brazil.

(2) Universidade Federal do Paraná, Brazil.

(3) NOVA University de Lisbon, Portugal.

${ }^{*}$ Corresponding author: sonia.parolin@gmail.com

ISSN: 0718-2724. (http://jotmi.org)

Journal of Technology Management \& Innovation @ Universidad Alberto Hurtado, Facultad de Economía y Negocios. 


\section{Methodological procedures}

\section{Bibliometric survey}

For the conception of the analytical model that supported the construction of the measurement instrument (EOC-CTI), a bibliometric survey was previously carried out on the following journal databases: Wiley, SAGE Journals, Social Science Citation Index / Web of Science, Scopus, DOAJ - Directory Open Articles Journal, SPELL - Scientific Periodicals Electronic Library, using combinations of search strings that covered the dimensions of the analysis. The following combinations of search strings were used: "organization ${ }^{\star}$ AND "culture*" AND "techn* innovation*"; "Organizational culture" AND "technological innovation"; "Antecedents" AND "organizational culture" AND "technological innovation"; "organization*" AND "culture AND "techn*” AND "innovation*".

Only complete peer-reviewed articles were considered. The final sample resulted in 62 articles that were read in their entirety as sources of research items, whose synthesis and analysis models are presented in the following section.

Extant research points out, in general, to the intensification of cooperation through different approaches, such as: incubators, local productive arrangements, sectorial and business studies, promotion and subvention, innovation networks, public policies, university-industry cooperation and technology transfer. Based on these items identified in literature, we performed the data collection that allowed the construction and validation of the instrument proposed here.

\section{Data collection for the construction of the instrument}

The research instrument construction was based upon the constructs that resulted from the bibliographic survey that composed the study variables. Initially, 71 closed questions were structured, with the adequate caution for avoiding the formulation of ambiguous, biased or negative questions (Cozby, 2003). A panel of six specialists in the area, with master's and doctorate level training, judged and evaluated the semantics of the items. After their assessment 59 revised questions were considered representative.

The instrument was then structured as a five-point Likert scale, in which the respondents should assess their agreement or disagreement (01-strongly disagree / 05-totally agree). At the end of the questionnaire, a specific section was reserved to collect biographical data with closed questions from various options on a nominal scale (Cozby, 2003; Roesch, 1999). A field called "organization code" was inserted, aiming to control the number of respondents per participating organization (research institutes: RI 00; or industry firm: IF 00). After the questionnaire was structure, it has gone through a new round of evaluation, this timey by a panel comprising four professionals with masters and doctoral degrees, experience with $\mathrm{R} \& \mathrm{D}$ and technological innovation evaluated. Two panel members were working in large firms (one in the automotive industry and the other in the home appliance industry), and the other two professionals were working at research institutes (one from a public university and the other from a private research institute). After the analysis of the panel of specialists, 59 questions were considered appropriate for the measurement instrument. The next step was the creation of the instrument in Google Forms platform. A new test was carried out, aiming at gathering suggestions for the apparent validity (Cozby, 2003) with seven respondents from a public research institute. No additional observations were made by this group of respondents.

The survey was carried out between July and November 2017. The link leading to the questionnaire was only provided after those in charge of the organizations had agreed to participate in the study. The sample was divide into two groups: research institute (public and private) and medium and large industries, both with $\mathrm{R} \& \mathrm{D}$ areas, innovation and development of new structured products. For the selection of research institutes and industries and subsequent contact with their managers, formal support was obtained from entities in the area of Science, Technology and Innovation operating at national level, in addition to the support of some Technological Innovation Centers from universities, industry associations and research institutes. Information from websites of different agencies in the ST\&I area, annual reports from the main incentive bodies in technological innovation in the country, among other sources of information collection, were used.

The sample consisted of 99 organizations, 58 of which are private industries (50 large and 8 medium-to-large firms), and 41 research institutes (17 private and 23 public, in various technological areas). The total number of respondents was 324 individuals: 159 from industry (49\%) and 165 from research institutes (51\%). The sample was composed of experienced professionals in technology and innovation, with a high academic background, being: $73.1 \%$ male, almost half of the group aged between 31 and 45 years old, $24.5 \%$ with a master's degree or in training and $24.8 \%$ with a doctorate or in training; $49.5 \%$ worked in the management area and $47.1 \%$ had been with the organization for more than 10 years and $23.2 \%$ between 5 and 10 years.

The research instrument consisted of 59 questions and, since the largest dimension contained 19 questions, it was possible to split the sample and save part of the data for the confirmatory analysis. Thus, the first group of questions was used for exploratory factor analysis and was composed by 200 randomly sampled-respondents. The second group, with the remaining 124, was used to confirm the hypothesized relationships. Thus, the main group had a minimum ratio of 10.5 respondents per question, a ratio considered sufficient (Hair, Black, Babi \& Anderson, 2014). For confirmatory analysis, this ratio was 6.5 , which is also considered acceptable.

\section{Statistical analysis}

Since it is in the interest of the analysis to verify the existing correlation structure between the questions in order to confirm and / or reformulate the previously considered structures (as shown in Figure 1), the statistical technique chosen was the Exploratory Factor Analysis (EFA).

All analysis was performed using the R-3.5.2 software. The technique used to extract the factors was Principal Component Analysis with Varimax rotation. This was the technique chosen for presenting 
results more consistent with theoretical and practical knowledge (Hair et al (2014). To verify the internal consistency of the questions within each factor, Cronbach's Alpha was calculated.

As a general rule of thumb, the choice of questions kept within each factor was the factor load greater than 0.45 , in just one factor. Questions that did not present a significant load on any factor, which presented cross-loads or low commonality $(<0.5)$, were also excluded. In cases of significant theoretical construction, some exceptions to this rule have been applied.

\section{Theoretical background}

Construction of the instrument "Evaluation of Organizational Culture for Cooperation in Technological Innovation (EOC-CTI)" To designate a company as innovative, organizational efforts must be continuous and progressive, and not just sporadic. Success in innovations result from organizations' previous dispositions (impregnated in culture and internalized by their members) to accept a variety of challenges posed by opportunities to innovate (Claver et al., 1998). The authors emphasize that technological innovation and organizational culture should not be understood by what the organization has at its disposal alone, such as, for example, a large infrastructure (tangible resources) for an R\&D department. Therefore, the training and conviction of the staff on the competitive advantage through innovation (intangible resources), which support a strong corporate culture, should be included. Firms with a culture of technology and innovation invest heavily in technology for the development of new products (Brettel \& Cleven, 2011) and present a strong integration between competitive strategies and a technological profile compatible with the desired innovation (Lopes et al., 2013).

The discovery of culture for innovation stems from several studies on organizational culture that are anchored in Edgar Schein (1984). They address the three levels of apprehension proposed by Schein (visible and audible artifacts and creations, shared values and basic underlying assumptions), which are increasingly recognized and internalized as true by the members of an organization and of generalized effect on the way an organization interacts with each of its stakeholders (Brettel \& Cleven, 2011, p. 254).

Dobni (2008) presents four groups of precedent variables to organizational culture for innovation, which, in turn, mediate performance in the organization's results (intention to innovate, infrastructure for the purposes of innovation, market orientation for innovation and context of implementation of innovation). The author considers that the levels of apprehension of the organizational culture can occur through the analysis of rational tools and processes, defined by the strategic architecture of the organization (visible artifacts) and, for Tidd et al. (2008, p. 98-104), its apprehension can occur at the level of visible artifacts that reflect innovation management ("the way we manage innovation around here"): its routines, its procedures, with an emphasis on project management skills, formal and informal structures, and which should be discontinued when they don 't demonstrate real efficacy.
These studies also indicate that there is no ideal corporate size when it comes to innovation. However, for technological innovation, it depends on several organizational factors related to corporate culture, such as: a flexible organizational structure; successful organizational culture based on technology and innovation; cohesion among its members; strategic management of human resources for valuing people; decision-making process aimed at a clear orientation towards the market, which adds value to the results in R\&D (Lau \& Ngo, 2004; Tidd et al., 2008).

The present study was based on the assumption that organizational culture is an intangible resource that cannot be directly measured (Brettel \& Cleven, 2011). Moreover, it is based upon the values that are shared within organizations, and it is possible to adopt new management practices of innovation and technology that could be more appropriate to obtain competitive advantages through the cooperation in technological innovation (Brettel \& Cleven, 2011; Dobni, 2008; Jensen, Johnson, Lorenz \& Lundvall, 2007; Peeters et al., 2014). Thus, this article expands the "culture for technological innovation" model proposed by Claver et al. (1998) by adding theoretical articulations and developing an research instrument that contemplate the aspects of organizational culture management that can influence cooperation for technological innovation. Two dimensions of study were established, which are discussed below: (a) values of the organizational culture for cooperation in technological innovation; and (b) management for cooperation in technological innovation.

\section{Values of Organizational Culture for Cooperation in Technological Innovation}

To compose the dimension "Values of Organizational Culture for Cooperation in Technological Innovation", the present study was based on the five variables proposed by Claver et al. (1998, p. 6265 ). This set of variables constitute the independent variables in the analytical model adopted in this research.

The first category, added value in $\mathbf{R} \& \mathbf{D}$, involves fostering a creativity for technological innovation that can flexibly cover cross-border cultural differences in collaboration between different partners (Barnes, Pashby \& Gibbons, 2006; Hecker , 2016); R\&D policies (internal and external) aimed at results through research (Claver et al., 1998; Jensen, et al., 2007); exploration of technologies (exploitation-exploration), depending on the types of cooperation (local and global), the types of partners (focused on the market or on scientific-technological development) and the governance mode (informal versus formal) of the collaborations (Brettel \& Cleven, 2011; Černe, Jaklič \& Škerlavaj, 2016; Sun \& Lo, 2014). This dimension also encompasses the different motivations between cooperation partners in the mobilization of knowledge, related to technology and knowledge transfer, access to new knowledge or to the solution of technological problems that can have an impact on competitiveness (Banholzer \& Vosejpka, 2011; Brettel \& Cleven , 2011; Jensen et al., 2007). As a result of this knowledge mobilization, it is that the interaction between partners provides "bilateral" and continuous learning to achieve an equilibrium between exploitation-exploration in cooperation (Shipton, Fay, West, Patterson \& Birdi, 2005). 
Additionally, the theoretical articulations in Claver et al. (1998) regarding human resource strategies were those aimed at obtaining results through innovation. Previous research points out to some recurring behaviors for technological innovation, such as freedom and autonomy to promote cooperation (formal and informal) with external partners, formation of interorganizational teams, among others (Claver et al., 1998; Feller et al., 2013; Hecker, 2016; Lau \& Ngo, 2004). Moreover, previous research also shows the conceptual integration between innovation strategy and human resource management for technological innovation, which analyze the HRM systems that influence more the results through technological innovation (Banholzer \& Vosejpka, 2011; Leede \& Looise, 2005; Park et al., 2017).

To compose the set of variables in the dimension on decision-making process, the following issues were considered; strategic decision making with the ability to act quickly and flexibly in the face of the challenges of R\&D and cooperation, the predisposition to accept high levels of risk (risk-taking) with innovation and shared responsibilities within the governance of cooperation (Banholzer \& Vosejpka, 2011; Claver et al., 1998; Dobni, 2008; Leede \& Looise, 2005; Park et al., 2017; Popadiuk \& Bido, 2016). The decision-making process on the choice of partners for cooperation expands into decisions that cover, for example, geographical distance, cooperation based on codified knowledge, infrastructure, reputation and prestige criteria related to the technological domain of the partner involved in the cooperation (Arvanitis et al., 2016; Bonfim, Gonçalves, Moreira \& Jacometti, 2016; Claver et al., 1998; de Faria et al., 2010; Fitjar \& Rodríguez-Pose, 2013; Savitskaya, Salmi \& Torkkeli, 2010; Okamuro \& Nishimura, 2013).

Regarding market orientation and results in cooperation for technological innovation, the literature addresses it from an R\&D development for long-term innovations perspective (Brettel \& Cleven, 2011; Claver et al., 1998; Popadiuk \& Bido, 2016). There are variations in the understandings between research institutes and firms. For example, research institutes aim at results that can strengthen their research groups (Bonfim et al., 2016; de Faria et al., 2010) and firms aim at reducing development time and cost in a manner they can achieve results that provide greater competitiveness in their markets (Claver et al., 1998; Savitskaya et al., 2010).

In terms of organizational structure, previous research shows the effectiveness of the most decentralized structures (Arvanitis et al., 2016; Claver et al., 1998; Popadiuk and Bido, 2016), of multi-organizational structures for technological innovation in cooperation (Jensen et al., 2007; Sun \& Lo, 2014) that encourages the work to be carried out by groups of multidisciplinary projects indicating the key people in various organizational support areas (Claver et al., 1998; Okamuro \& Nishimura, 2013; Shipton et al., 2005; Sun \& Lo, 2014). The emphasis is on the wide communication as one of the central components for trust and effectiveness of cooperation for R\&D (Feller et al., 2013; Hecker, 2016; Tidd et al., 2008).

\section{Management for Cooperation in Technological Innovation}

With regard to the construct "Management for Cooperation in Technological Innovation", it is important to reaffirm that, for Lopes et al.
(2013), technology management can occur in many forms and places within organizations. However, organizations need to keep their technological profile compatible with the desired innovation outcome. On the other hand, innovation management can occur within the organization as a whole, through the adoption of new management practices that can impact on firms' performance, on new processes and on new structures and techniques (Černe et al., 2016; Peeters et al., 2014). In other words, non-technological innovations may also occur as a result of a strong culture for innovation (Brettel \& Cleven, 2011). Additionally, while technological innovation requires a lot of energy get to the invention and to refine them as superior products and to establish an orientation towards new technology development and learning (Brettel \& Cleven, 2011), traditional methods of technological measurement are considered insufficient to detect the essence of the innovative process in its entirety (Fornari et al., 2014). In this regard, it is possible to perceive additional peculiarities in the management for technological innovation that converge with the essence of what was proposed by Claver et al. (1998), that is, a culture for technological innovation originates from an organizational culture for innovation embedded in organizational strategy.

As previously mentioned, scant attention has been given to organizational culture as a determinant of management practices aimed at cooperation for technological innovation. Thus, there is a need to improve scholarly understanding about how to implement and manage effective routines, to improve performance and encourage cooperation between organizations for R\&D collaboration (Feller et al., 2013; Van Beers \& Zand, 2013; Wikhamn \& Styhere, 2017). Thus, in order to compose the independent variables of this dimension, management and support practices for cooperation in technological innovation in areas within the organization were considered. These included administrative and financial areas related to technological innovation projects, marketing for innovation, accounting practices for adding value to innovation, such as those related to R\&D management (Banholzer \& Vosejpka, 2011; Černe et al., 2016; Degtyarova et al., 2016; Dobni, 2008; Kerzner, 2003; Tidd et al., 2008). This dimension of analysis also encompassed the variables related to technological innovation and project management practices and tools (Kerzner, 2003; Tidd et al., 2008), as well as the interaction between partners in processes of project management in cooperation (Schwartz et al., 2012). In the legal area, strategies and practices of intellectual property within the scope of cooperation were included (Banholzer \& Vosejpka, 2011; Sun \& Lo, 2014; Okamuro \& Nishimura, 2013; Wu, Wang \& Chen, 2017).

A set of variables was used to support technological innovation practices that refer to: agreements for technology acquisition and transfer (Okamuro \& Nishimura, 2013; Sbragia et al., 2006), and identification of technological trends for R\&D projects (Tidd et al., 2008). In the Brazilian context, technical support is considered for the identification and application of public and fiscal incentives for technological innovation projects (Sbragia et al., 2006).

The analytical model is presented in Figure 1, which aims to graphically demonstrate the objective of analyzing the values of the organizational culture that influence management for cooperation in technological innovation between firms and research institutes. 
Figure 1: Research model.

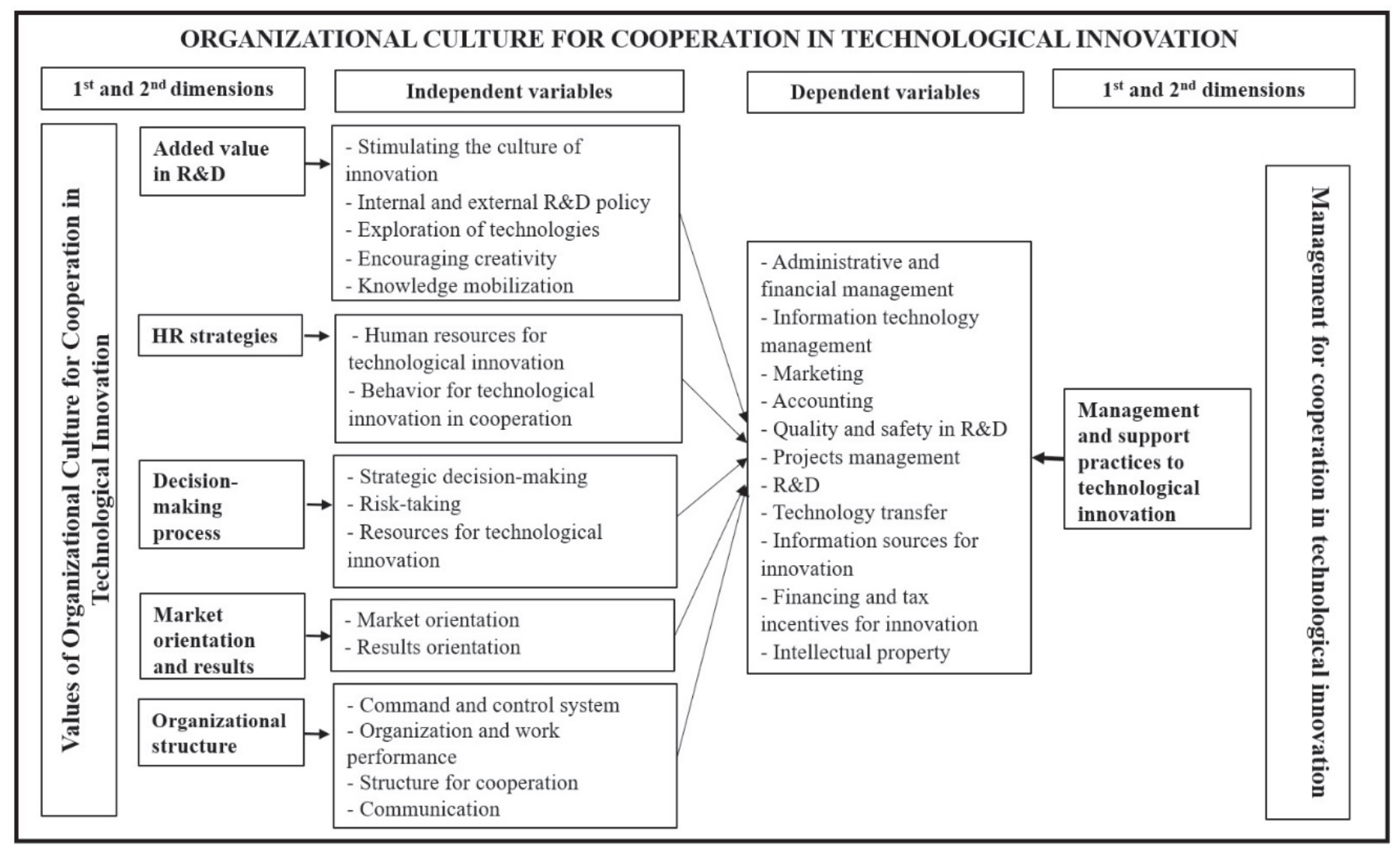

\section{Validation of the instrument "Evaluation of Organiza- tional Culture for Cooperation in Technological Innovation"}

The composition of the initial scale and its dimensions are presented in this section. Moreover, the analyzes performed and the respective questions that were maintained in each factor are presented as well.

\section{Independent variables: Values of Culture for Cooperation in Tech- nological Innovation}

The dimension "added value in R\&D" initially considered the existence of five latent constructs, formed by the grouping of 11 questions, as demonstrated in Appendix C.

The first step of factor analysis was to analyze the data according to its assumptions by means of the correlation matrix, Bartlett's test, KMO (Kaiser-Meyer-Olkin Test) and MSA (Measures of Sampling Adequacy).

The correlation matrix showed an elevated number of correlations above 0.3 , indicating that it was adequate for the factor analysis. The Bartlett's test also showed a p-value $<0.0001$, and the KMO result was 0.85 . Analyzing each question separately, only the question 04 (q04) was excluded because it had a MSA below the recommended threshold (0.35).

Considering the latent root criterion and the scree test, initial analysis pointed to the definition between 2 and 3 factors. The two-factor solution was chosen because it has eigenvalues greater than 1 , the lower being 1.47, explaining 59\% of the variance. Question 11 (q11) had low commonality (0.48) and therefor it was also excluded from the model. After excluding this question, the final two-factor solution explains $61 \%$ of the total variance.

The first factor of this dimension was called stimulating technological innovation and it included seven questions, with the lowest load being 0.64 (all positive loads). The question 07 (q07) obtained the lowest commonality, 0.50 . The second factor called knowledge mobilization included two questions with the same load, 0.86 . For assessing the internal consistency, the Cronbach's alpha was calculated resulting in coefficients of 0.87 for the factor 1 and 0.68 for the factor 2 .

Running the analysis with a separate sample for validation, similar solutions were found. The main difference was that question 10 had cross-loadings, but with a higher value for the factor 1 .

The second dimension of the initial construct analyzed was human resource strategies, considering, initially, the existence of seven questions distributed by two factors (Appendix C).

Additionally, for this second dimension, the analysis of the correlation matrix showed a high number of correlations higher than 0.3. Both the Bartlett and the KMO tests were significant (Bartlett with pvalue $<0.0001$ and $\mathrm{KMO}$ of 0.78 ). Thus, as the set of questions proved to be suitable for the application of factor analysis, and all questions were maintained. 
The initial analysis suggested the formation of two to three factors. The final solution considered two factors, both because of its practical interpretation and because they explained $57 \%$ of the variance. After the rotation, the question 15 (q15) was excluded due to its low commonality. Question 12 (q12) also had low commonality (0.44) but was maintained due to its practical interpretation. After excluding these questions, the final solution had with two factors explaining $70 \%$ of the variance. The two factors, both with the permanence of three questions in each, were entitled human resources for technological innovation and behavior for cooperation in technological innovation.

Only the question 12 (q12) had commonality below 0.50 (0.46), and the confirmatory analysis showed similar results. Only question 16 (q16) had cross-loadings but remained with higher value in the factor "Human resources for technological innovation". Analyzing the internal consistency, a Cronbach's alpha of 0.82 was obtained for factor 1 and 0.72 for factor 2 .

The third dimension, decision-making process, initially considered 12 questions, divided in three latent constructs (Appendix C).

Analyzing the correlation matrix, it was possible to identify a high number of correlations higher than 0.30 . Bartlett's test presented a p-value lower than 0.001 and the KMO was 0.83 .

The initial analysis latent root criterion and scree test indicated that the definition of two to four factors would be adequate. The threefactor solution was chosen, initially, due to its theoretical consistency. Moreover, clarifies a reasonable percentage of the variance (55\%). This was also the last factor with an eigenvalue higher than 1.09. Some questions had low commonality or cross-loads and therefore were excluded (questions 19, 20, 21 and 22). After excluding these questions, the final solution indicated two factors that explained $62 \%$ of the total variance, which were called strategic decision-making (composed of six questions), and resources with cooperation (with two questions).

Although some questions presented commonality lower than 0.5 ( 0.48 and 0.44 for questions 23 and 24, respectively), they were kept due to their theoretical importance. Confirmatory analysis had similar results. Analyzing the internal consistency using the Cronbach's alpha, the values were 0.85 for factor 1 , and 0.67 for factor 2 .

The fourth dimension, market orientation and results, contained four questions in two latent constructs (Appendix C).
Both the correlation matrix analysis and the KMO tests presented values showing that the data were conducive to the application of factor analysis. Bartlett's test had a p-value $<0.001$ and the KMO was 0.56 .

The initial analysis of the scree plot, eigenvalues and explained variance, suggested the definition of two factors. The final solution explains $77 \%$ of the variance.

The results followed the expected grouping and the factors maintained the previously defined nomenclature. When the factor analysis was performed, with the base reserved for validation, the same results were found. The internal consistency index, which was assessed through the Cronbach's alpha, was 0.70 for the first factor and 0.69 for the second factor.

The fifth dimension, organizational structure, initially contained six questions, divided into four latent constructs (Appendix C).

Analyzing the correlation matrix, several correlations above 0.3 can be observed. Bartlett's test showed a p-value <- 0.001 and the KMO was 0.83 , indicating that the basis was favorable for factor analysis. No question needed to be ruled out.

The three-factor solution was chosen because it presented more theoretical reason and explains $74 \%$ of the variance. However, two factors were left with only one question (factor 2 with question 35 and factor 3 with question 38). For this reason, these questions have been excluded.

After excluding the two questions (q35 and q38), the final solution was left with two factors and explains $76 \%$ of the variance. Question 36 had cross-loadings and kept in the factor in which it had the greatest load and theoretical meaning.

Both factors were composed of two questions each, the first factor being called communication and the second structures for cooperation, as can be seen in Table 6 .

No question presented commonality lower than 0.5 and the validation showed similar results. Question 36 continued with crossloadings, but with higher weight in the "Communication" factor. The internal consistency of the first factor was 0.71 and the second factor was 0.63 . 
Table 1: Latent constructs resulting in the dimension "values of the organizational culture for cooperation in technological innovation"

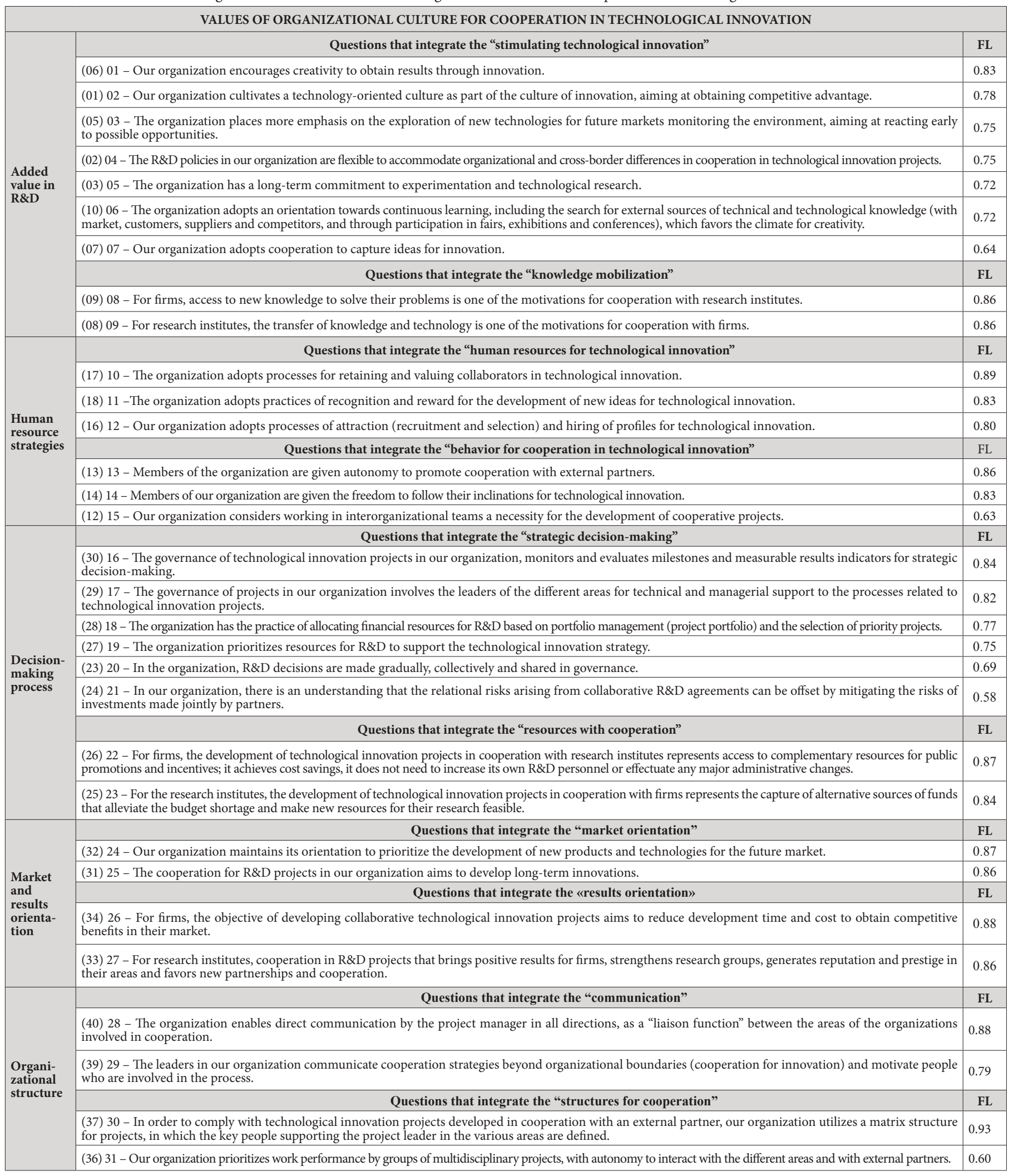

Source: Elaborated by the authors (2020).

Comments:

- the number in parentheses indicates the position in the initial research instrument. The following numbers indicate the new sequence after statistical validation; - FL: factor load. 


\section{Dependent variables: Management for Cooperation in Technological Innovation}

The sixth dimension considered, management practices for cooperation in technological innovation, initially contained 19 questions grouped into 11 latent constructs (Appendix C).

The correlation matrix showed several correlations higher than 0.3. Bartlett's test also gave a p-value lower than 0.001 and the KMO was 0.92 , with no indication of restrictions for the application of the factor analysis. Question 58 got a low MAS (0.46) and was excluded.

The analysis of eigenvalues and the scree plot indicated the creation of up to two to four factors, and the four-factor solution was chosen because it makes more theoretical sense and explains $64 \%$ of the variance.
Question 48 had cross-loadings and was excluded. Question 56 also presented cross-loadings. However, it was maintained in the first factor due to its theoretical importance, where it had a higher load and greater theoretical sense. Questions 46, 48, 50 and 53 were excluded due to their low commonality. Thus, the final solution had four factors, explaining $64 \%$ of the variance, and were named, respectively, "Support for technological innovation" and "Project management practices", with five questions each factor, "Intellectual property" and "Infrastructure Laboratory for R\&D ” with two questions in each factor (Appendix C).

Checking the internal consistency index, the values obtained were $0.83,0.83,0.66$ and 0.69 for factors $1,2,3$ and 4 , respectively. The factor analysis with the validation base obtained several questions with cross loadings. This result was probably due to the low relationship between the number of respondents and the total number of questions in dimension (6.5), with the definition by question allocation following the results of the exploratory analysis.

Table 2: Latent constructs resulting in the dimension "management for cooperation in technological innovation"

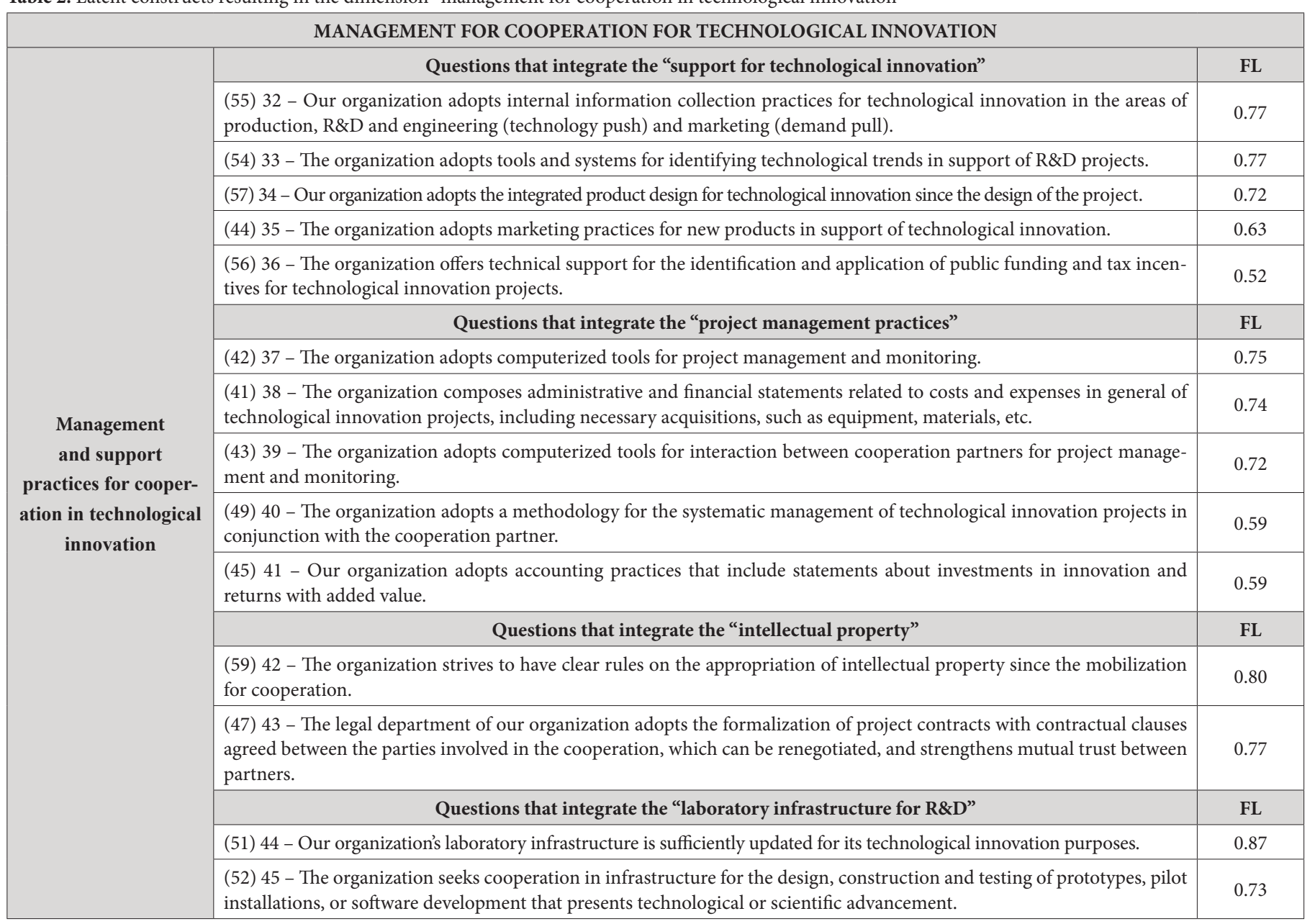

Source: Elaborated by the authors (2020).

Comments:

- the number in parentheses indicates the position in the initial research instrument. The following numbers indicate the new sequence after statistical validation;

- FL: factor load. 


\section{Discussion and conclusion}

This article proposed the construction, analysis and validation of a measurement instrument on the values of the organizational culture that influence management for cooperation in technological innovation. Based on the purpose of verifying the existing correlation structure between the questions that compose the research model with the use of EFA, the reformulation of the previous model was obtained, with a reduction from 28 to 14 factors, and from 59 to 45 questions. The exclusion of variables is a common procedure, as it intends to achieve a set of items adhering to the model with sufficient strength to explain it (Pedhauzur, 1997).

Due to the objective proposed in the study, the results suggest an organizational culture for cooperation in technological innovation encompasses values that influence and shape innovation management policies and practices, as well as practices to support technological innovation, with the reach of different areas and functions in the organization.

In the dimension of independent variables, the main results in added value in R\&D present the most significant factor loads in the values that encourage creativity and the development of new technologies, with the mobilization of knowledge between partners in cooperation. The literature addresses the different motivations between partners in cooperation (Banholzer \& Vosejpka, 2011; Brettel \& Cleven, 2011; Shipton et al., 2005). The present research advances this focus considering that the diversity of motivations in the interaction between the partners consist of the relevant element of "bilateral" continuous learning among its actors, constituting an approach to be further investigated.

In human resource management strategies, the results corroborate the literature that advocates valuing people in an organizational culture aimed at achieving results through innovation (Arvanitis et al., 2016; Lau \& Ngo, 2004; Leede \& Looise, 2005; Tidd et al., 2008). The emphasis on the set of results in the variables that compose the behavior for cooperation in technological innovation is distinctive, which denote the relevance of the composition of inter-organizational teams in cooperative projects, with autonomy and freedom to innovate. These results are in line with encouraging creativity in added value in $R \& D$ and reflections by Arvanitis et al. (2016) on the relevance of new human resource management practices that encourage them to think independently, creatively and that result in greater motivation in the work environment. A deeper study on how these behaviors influence the results through innovation obtained in the dynamic of cooperation is suggested, considering the different organizational values and human resource management practices among the partners.

In the decision-making process, the analyzes resulted in significant factor loads in the governance of projects in technological innovation (R\&D) beyond organizational boundaries (Barnes et al., 2006), being that in resources for innovation the clarity in the distinction about the different interests and formats of access to complementary resources by the organizations involved, a clarity in the distinction similar to that demonstrated in knowledge mobilization. It should be noted that in results orientation, when positive for firms, they corroborate the literature by emphasizing the strengthening of the reputation and prestige of the research institutes that participated in the cooperation (Bonfim et al., 2016; Olavarrieta \& Friedmann, 2008). The model of analysis studied addressed decision-making processes for choosing partners for cooperation, considering criteria of reputation, prestige and geographical distance/proximity. This last variable, despite having been excluded in the validation of the model because it has an MSA of 0.50 , is a relevant theme to be developed by local innovation ecosystems, as it covers the influences of components of the macroenvironment in these relationships and considers that different types of partners lead to different types of innovations (Fitjar \& RodríguezPose, 2013). Another point to consider is that the development of projects and the mobilization of learning and knowledge is affected by the geographical distance between partners, since research has shown that partnerships with face-to-face collaboration are more likely to be more innovative than the ones with long-distance collaboration (Hage \& Hollingsworth, 2000).

In the variables referring to market orientation and results, the factor loads were significant in all of them, without altering the analytical model adopted. The validation of the instrument shows that the different approaches in this construct between firms and research institutes do not invalidate cooperation. Future research can investigate whether the type of exploitation of technologies (exploitation-exploration) involved in the cooperation changed the perception of market orientation and results by the partners involved in the cooperation (Park et al., 2017; Yoon et al., 2017).

Within the results in organizational structure, it was noticed that the final solution in two factors, with the retaining of four questions among the initial six, gave greater cohesion to the construct, and question 37 (initial numbering), related to the matrix structure with key people in the areas to support the project leader, presented the highest factor load of the research. This result converges with human resource strategies, in which autonomy (initial q13) and freedom (initial q14) are encouraged in the organizational environment. As a consequence, these results suggest that these matrix structures support governance (q29 and initial q30), which favors the accumulation of reputation and trust among cooperation partners (Bonfim et al., 2016; Olavarrieta \& Friedmann, 2008).

In the dimension of the dependent variables, the reduction from 12 initial constructs, with 19 questions distributed among them, to four constructs with 14 questions, established management practices and support for cooperation in technological innovation as more objective. The theoretical discussions included in this dimension are usually held separately, given their importance and depth as specific areas of knowledge (for example: project management practices, intellectual property, marketing for new products, innovation encouragement, etc.). The latent construct, resulting in management for cooperation in technological innovation, considered the practices present in an organizational culture that influence the achievement of results in innovation in cooperation (Brettel \& Ceven, 2011; Dobni, 2008; Peter et 
al., 2014). Note that considering Claver's et al. (1998) model, which makes the conceptual distinction between "innovation-oriented culture" (innovation not related to technology) as the principle shared value and which includes "culture for technological innovation" (which considers culture for technology), the practices suggested here follow this conceptual logic.

Finally, we draw attention to the emphasis on governance of cooperation, with the involvement of partners both in strategic decisions as in the management of projects in cooperation, with practices that demonstrate added value with cooperation, which refers to Claver et al. (1998) on the staff's conviction for a strong corporate culture for innovation, with reflections on the structures, routines and procedures in the organization (Tidd et al., 2008).

Based on the theoretical articulations carried out in this research, it was found that it presents theoretical and practical contributions regarding the factors that corroborate cooperation and which systematic management practices and support for technological innovation provide sustenance for long-term cooperation strategies. The article proposes a model on organizational culture for cooperation in technological innovation, as shown in Figure 2 below.

Figure 2: "Organizational culture model for cooperation in technological innovation".

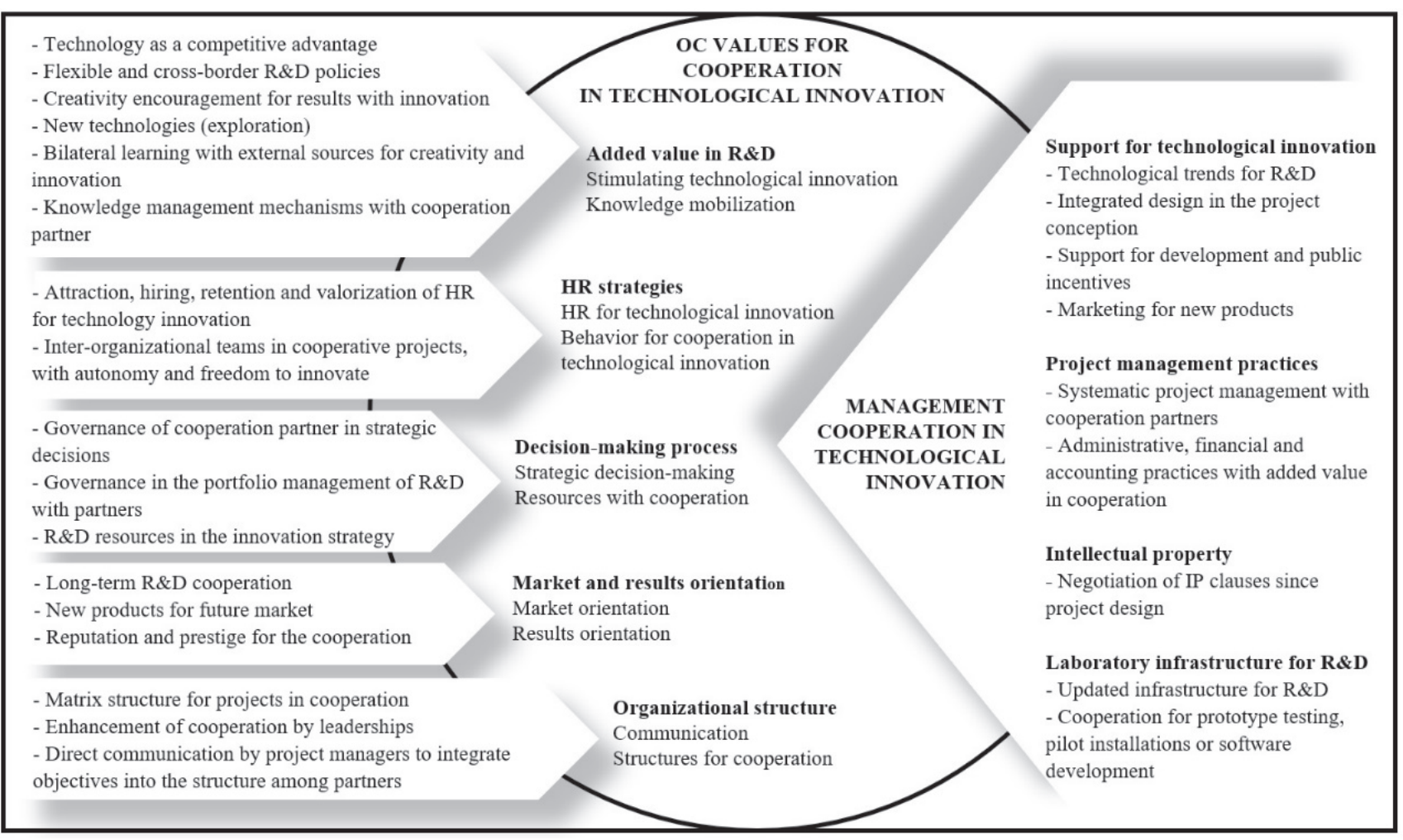

A comparative study is suggested between the types of organizations (firms, public and private research institutes) to identify the differences and similarities in each dimension of the organizational culture for the continuous cooperation in technological innovation, in order to contribute to the advancement of discussions on the theme.

As a practical implication, the study points out elements of management of technological innovation aimed at cooperation, which are more evident by the large industries and research institutes in the country, to obtain results with technological innovation and sustainable competitive advantage. These results can subsidize organizational design for cooperation strategies and practices.

The limitations of the study refer to the scope of the construct, which requires theoretical developments in order to deepen the discussions around the proposed scope. Qualitative studies may contribute to the triangulation of analyzes and to deepen the construct. Notwithstanding, this research provided an outline of scope consistent with the trends of cooperation in which the organizational boundaries expand and, therefore, the adaptive processes of the organizational culture expand.

\section{References}

Alves F.S., Segatto, A.P., De-Carli, E. (2016). Theoretical framework about relational capability on inter-organizational cooperation. Journal of Industrial Integration and Management, 1(04): 1650012, DOI: $10.1142 /$ S2424862216500123.

Arvanitis, S., Seliger, F. and Stucki, T. (2016). The relative importance of human resource management practices for innovation. Economics of Innovation and New Technology, 25(8): 769-800, DOI: 10.1080/10438599.2016.1158533. 
Banholzer, W.F. and Vosejpka, L.J. (2011). Risk Taking and Effective R\&D Management. Annual Review of Chemical Biomolecular Engineering, 2:173-188, DOI: 10.1146/annurev-chembioeng-061010-114241.

Barnes, T. A., Pashby, I. R. and Gibbons, A. M. (2006). Managing collaborative R\&D projects development of a practical management tool. International Journal of Project Management. 24, 395-404, DOI: 10.1016/j.ijproman.2006.03.003.

Bonfim, L.R.C., Gonçalves, S.A., Moreira, M.S. and Jacometti, M. (2016). Institutional Entrepreneurship and Improvement of Quality of Life: The Formation and Legitimation of a Public- Private Innovation Network in Molecular Biology Applied to Public Health in Southern Brazil. In: J. Leitão and H. Alves, Innovative and entrepreneurial practices in public institutions: a quality-of-life approach, 123-154, Cham: Springer.

Brettel, M. and Cleven, N.J. (2011). Innovation Culture, Collaboration with External Partners and NPD Performance aim. Creativity and Innovation Management Journal, 20(4): 253-272, DOI: 10.1111/ j.1467-8691.2011.00617. x.

Černe, M. Jaklič, M. \& Škerlavaj, M. (2016). Management innovation enters the game: Re-considering the link between technological innovation and financial performance. Innovation, Management, Policy \& Practice, 01-21, DOI: 10.1080/14479338.2015.1126530.

Claver, E., Llopis, J., Garcia, D. and Molina, H. (1998). Organizational culture for innovation and new technological behavior. Journal of High Technology Management Research, 9(1): 55-68, DOI: 10.1016/1047-8310(88)90005-3.

Cozby, P.C. (2003). Métodos de pesquisa em ciências do comportamento. Trad. Paula Inez Cunha Gomide, Emma Otta. SP: Atlas.

de Faria, P., Lima, F. and Santos, R. (2010). Cooperation in innovation activities: The importance of partners. Research Policy, 39(8): 10821092, DOI: 10.1016/j.respol.2010.05.003.

Degtyarova, I., Tokareva, G., Shalina, O. and Fedorenko, O. (2016). Excellence of Innovative activity management at the Russian enterprises. International Journal for Quality Research, 10(4): 785-798, DOI: 10.18421/IJQR10.04-09.

Dobni, C.B. (2008). Measuring innovation culture in organizations. European Journal of Innovation Management, 11(4): 539-559, DOI: 10.1108/14601060810911156.

Feller, J., Parhankangas, A., Smeds, R. and Jaatinen, M. (2013). How Companies Learn to Collaborate: Emergence of Improved Inter-Organizational Processes in R\&D Alliances. Organization Studies. 34(3): 313-343, DOI: 10.1177/0170840612464758.

Fitjar, R.D. and Rodríguez-Pose, A. (2013). Firm collaboration and modes of innovation in Norway. Research Policy, 42: 128-138, DOI: 10.1016/j.respol.2012.05.009.
Fornari, V.C.B, Gomes, R. and Correa, A.L. (2015). Indicadores de inovação: um exame das atividades inovativas na indústria internacional de alimentos processados. Revista Brasileira de Inovação, 14(1): 135-162, DOI: 10.20396/rbi.v14i1.8649092.

Hage, J., Hollingsworth, J.R. (2000). A strategy for the analysis of idea innovation networks and institutions. Organization Studies, 21(5): 971-1004, DOI: 10.1177/0170840600215006

Hair, J.F., Black, W.C., Babi, B.J., Anderson, R.E. (2014). Multivariate data analysis. 7th New International Edition. Essex, UK: Pearson. Hecker, A. (2016). Cultural contingencies of open innovation strategies. International Journal of Innovation Management, 20(7): 1650067, DOI: $10.1142 / \mathrm{s} 1363919616500675$.

Jensen, M.B., Johnson, B., Lorenz, E. and Lundvall, B. (2007). Forms of knowledge and modes of innovation. Research Policy, 36: 680-693, DOI: 10.1016/j.respol.2007.01.006.

Kerzner, H. (2003). Project Management: a systems approach to planning, scheduling and controlling (8a. Ed.) New Jersey, John Wiley \& Sons, Inc.

Lau, C.-M. and Ngo, H.-Y. (2004). The HR systems, organizational culture and product innovation. International Business Review, 13: 685-703. DOI: 0.1016/j.ibusrev.2004.08.001.

Laursen, K. and Salter, A. (2006). Open for innovation: the role of openness in explaining innovation performance among U.K. manufacturing firms. Strategic Management Journal, 27: 131-150, DOI: 10.1002/smj.507.

Leede, J. de and Looise, J. K. (2005). Innovation and HRM: Towards an Integrated Framework. Creativity and Innovation Management Journal, 14(2): 108-117, DOI: 10.1111/j.1467-8691.2005.00331. x.

Lopes, E.M., Fontão, H. e Gonçalves, A.S. (2013). Significant factors in the technological profile of innovative companies in the return of capital in technological innovation. International Journal of Innovation, SP, 1(1): 43-61, jan/dec, DOI: 10.5585/iji.v1i1.10.

Okamuro, H. and Nishimura, J. (2013). Impact of university intellectual property policy on the performance of university-industry research collaboration. Journal of Technology Transfer, 38: 273-301, DOI: 10.1007/s10961-012-9253-z.

Park, O., Bae, J. and Hong, W. (2017). High-commitment HRM system, HR capability, and ambidextrous technological innovation. The International Journal of Human Resource Management, DOI: 10.1080/09585192.2017.1296880.

Pedhauzur, E.J. (1997). Multiple regression in behavioral research: explanation and prediction. 3a.ed. Fort Worth: Harcourt Brace J. College Publishers.

Peeters, C., Massini, S. e Lewin, A. (2014). Sources of variation in the efficiency of adopting management innovation: the role of absorptive capacity routines, managerial attention and organizational legitimacy. Organization Studies, vol. 35(9), p. 1343-1371, DOI: 0.1177/0170840614539311. 
Popadiuk, S., and Bido, D.D.S. (2016). Exploration, exploitation, and organizational coordination mechanisms. Revista de Administração Contemporânea, 20(2): 238-260, DOI: 1 0.1590/19827849rac2016150018.

Savitskaya, I., Salmi, P. and Torkkeli, M. (2010). Barriers to Open Innovation: Case China. Journal of Technology Management \& Innovation, 5(4): 10-21, ISSN: 0718-2724.

Sbragia, R. (Coordinator), Stal, E., Campanário, M. and Andreassi, T. (2006). Inovação: como vencer esse desafio empresarial. São Paulo: Clio Editora.

Schein, E. (1984). Coming to a new awareness of organizational culture. Sloan Management Review, 25(2): 3

Schwartz, M., Peglow, F., Fritsch, M. and Günther, J. (2012). What drives innovation output from subsidized R\&D cooperation? Projectlevel evidence from Germany. Technovation, 32: 358-369, DOI: 10.1016/j.technovation.2012.03.004.

Shipton, H., Fay, D., West, M., Patterson, M. and Birdi, K. (2005). Managing people to promote innovation. Creativity and Innovation Management Journal, 14(2): 118-128, DOI: 10.1111/j.14678691.2005.00332. $\mathrm{x}$
Sun, B. and Lo, Y.-J. (2014). Achieving alliance ambidexterity through managing paradoxes of cooperation A new theoretical framework. European Journal of Innovation Management, 17(2): 144-165, DOI: 10.1108/EJIM-01-2013-0011.

Tidd, J., Bessant, J. and Pavitt, K. (2008). Gestão da inovação. 3a. Ed. Porto Alegre: Bookman.

Van Beers, C. and Zand, F. (2013). R\&D Cooperation, Partner Diversity, and Innovation Performance: An Empirical Analysis. Journal Prod Innovation Management, (2):292-312, DOI: 10.1111/jpim.12096.

Wikhamn, B.R. and Styhere, A. (2017). Open innovation as a facilitator for corporate exploration. International Journal of Innovation Management. 21(6) 1750042 (20 pages), DOI: 10.1142/ s1363919617500426.

Wu, A., Wang Z. and Chen, S. (2017). Impact of specific investments, governance mechanisms and behaviors on the performance of cooperative innovation projects. International Journal of Project Management, 35(3): 504-515, DOI: http://doi.org/f93srq.

Acknowledgments: this work was carried out with the support of the Coordination for the Improvement of Higher Education Personnel Brazil (CAPES) - Financing Code 001. 
Appendix A: Graphics of the Scree Plot compared to the independent and dependent variables

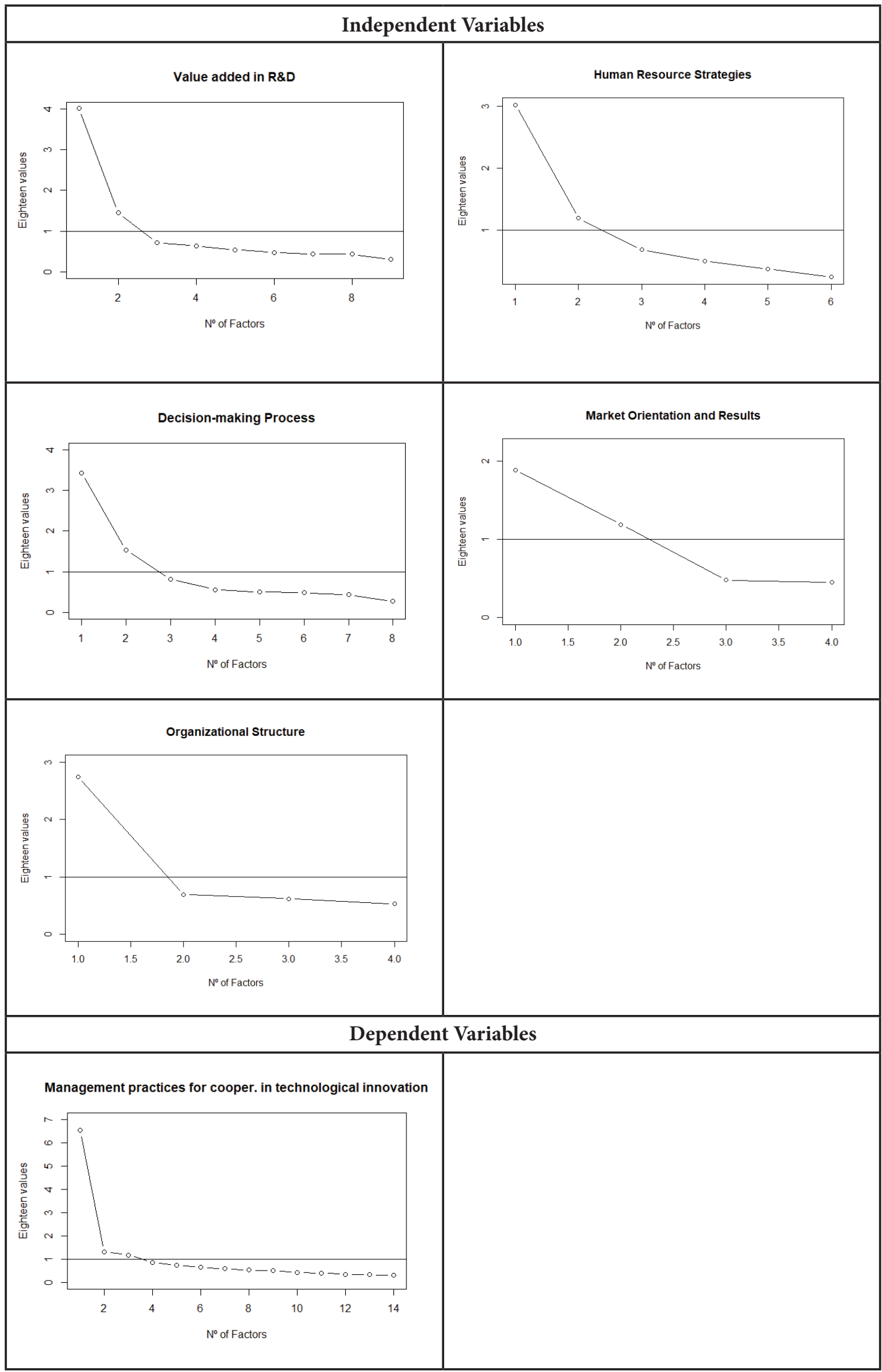


Appendix B: Graphics of the Factor Plot compared to the independent and dependent variables

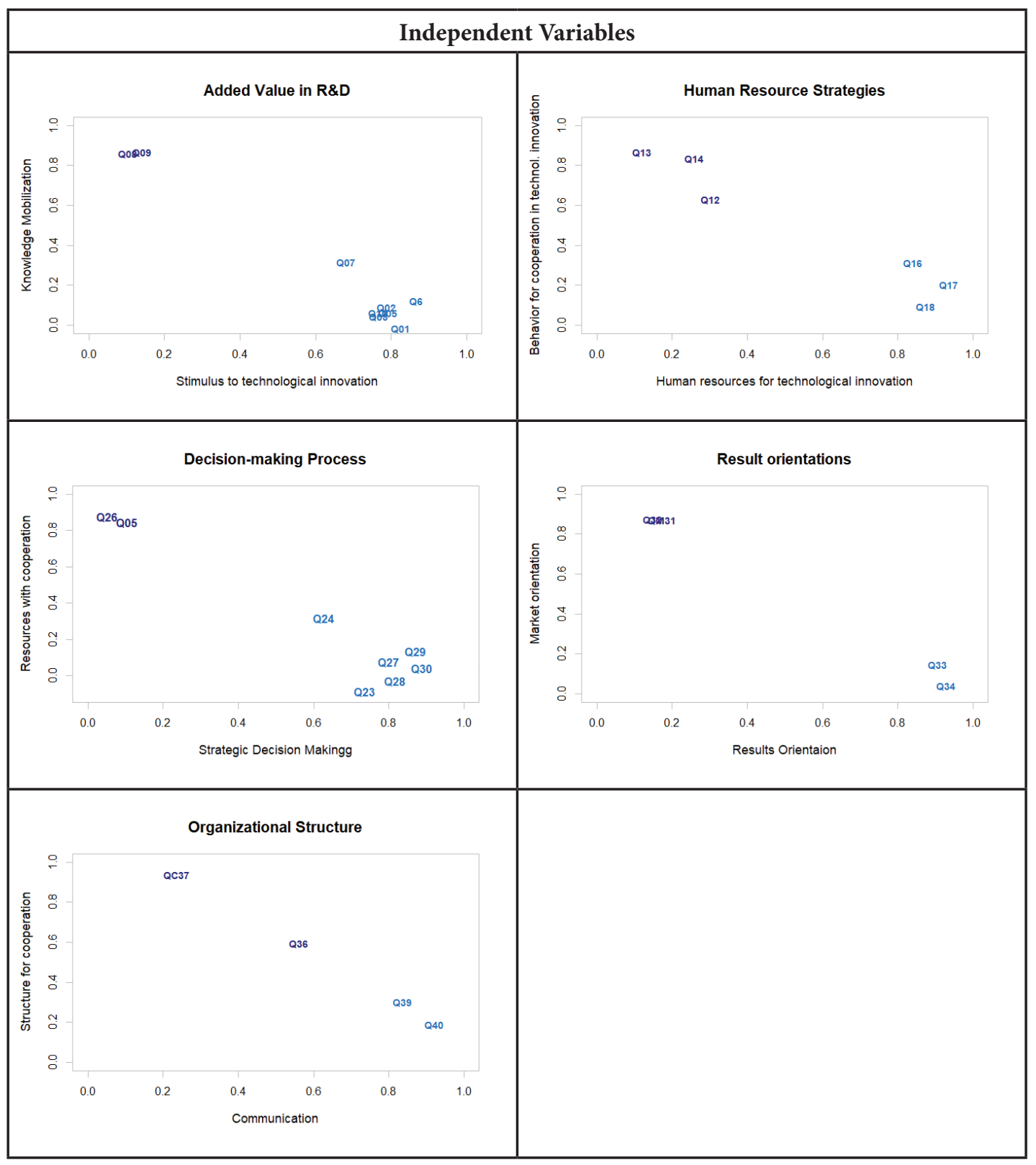




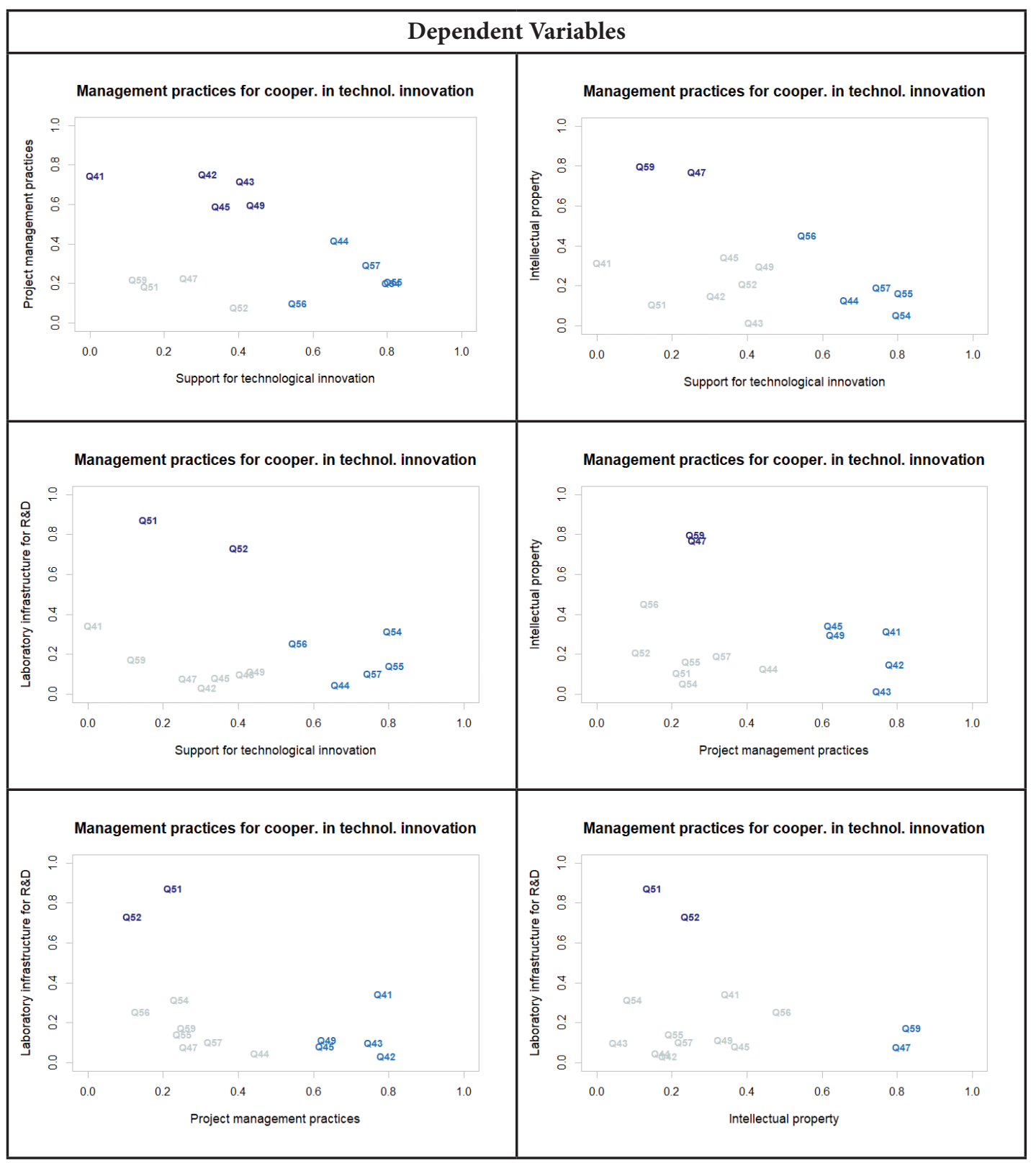




\section{Appendix C: Initial latent constructs in independent and dependent variables}

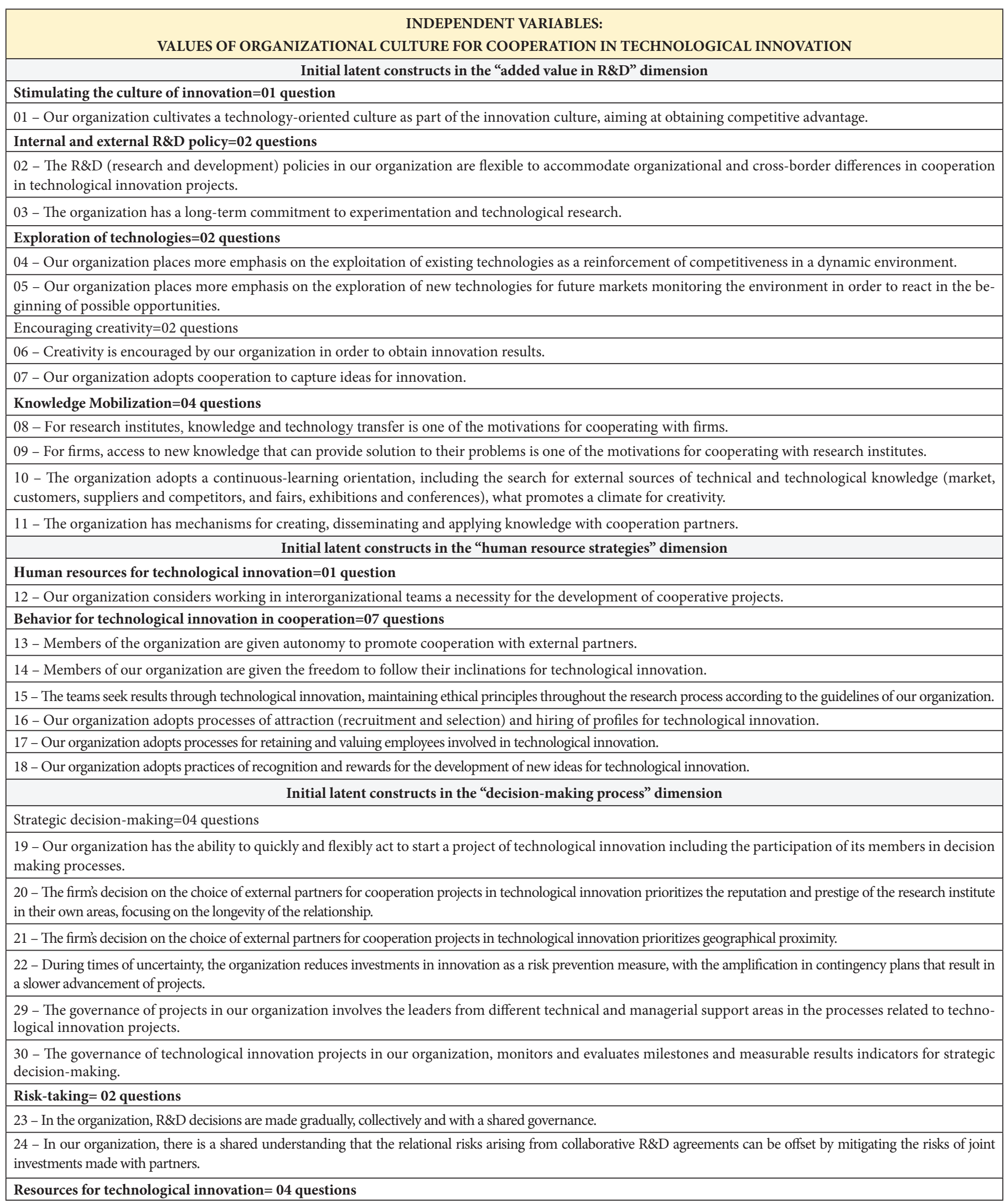


25 - For the research institutes, the development of technological innovation projects in cooperation with firms represent the alternative sources of funding that alleviate budget shortages and bring new resources for their research.

26 - For firms, the development of technological innovation projects in cooperation with research institutes represents the access to complementary resources for promotions and incentives; it provides cost savings, it does not require the increase in their own R\&D personnel or any major administrative change.

27 - The organization prioritizes resources for R\&D to support the strategy for technological innovation.

28 - The organization has the practice of allocating financial resources for R\&D based on portfolio management (project portfolio) and the selection of priority projects. Initial latent constructs in the "market orientation and results" dimension

\section{Market orientation $=02$ questions}

31 - The cooperation for R\&D projects in our organization aims at developing long-term innovations.

32 - Our organization maintains its orientation to prioritize the development of new products and technologies for the future market.

Results orientation $=\mathbf{0 2}$ questions

33 - For research institutes, cooperation in R\&D projects that brings positive results for firms, strengthens research groups, generates reputation and prestige in their areas and favors new partnerships and cooperation.

34 - For firms, the objective of developing collaborative technological innovation projects is to reduce development time and cost for obtaining competitive benefits in their market.

Initial latent constructs in the "organizational structure" dimension

Command and control system $=01$ question

35 - Our organization have a decentralized structure, with key rules for individuals (more generic) for solving occasional or common problems related to projects.

Organization and work performance $=01$ question

36 - Our organization prioritizes work performance by groups of multidisciplinary projects, with autonomy to interact with different areas and with external partners. Structure for cooperation $=02$ questions

37 - In order to comply with technological innovation projects developed in cooperation with an external partner, our organization utilizes a matrix structure for projects, in which are defined the key people supporting the project leader in the various areas.

38 - The multi-organizational structure for cooperative technological innovation projects allows for more efficient project management, but requires additional integration skills by the project manager.

Communication $=02$ questions

39 - The leaders in our organization communicate cooperation strategies beyond organizational boundaries (cooperation for innovation) and motivate people who are involved in the process.

40 - The organization enables direct communication by the project manager in all directions, as a "liaison function" between the areas of the organizations involved in cooperation.

\section{VARIABLES INDEPENDENTS: \\ MANAGEMENT FOR COOPERATION IN TECHNOLOGICAL INNOVATION}

Initial latent constructs in the "management practices for cooperation in technological innovation" dimension

Administrative and financial management $=01$ question

41 - The organization composes administrative and financial statements related to costs and expenses in general of technological innovation projects, including necessary acquisitions, such as equipment, materials, etc.

Information technology management $=\mathbf{0 2}$ questions

42 - The organization adopts computerized tools for project management and monitoring.

43- The organization adopts computerized tools for interaction between cooperation partners for project management and monitoring.

Marketing=01 question

44 - The organization adopts marketing practices for new products to support technological innovation.

Accounting $=01$ question

45 - Our organization adopts accounting practices that include statements about investments in innovation and returns with added value.

Quality and safety in $\mathrm{R} \& \mathrm{D}=\mathbf{0 1}$ question

46 - Our organization has a quality control and safety system at work, distinctly focused on R\&D.

Legal proceedings $=01$ question

47 - The legal department of our organization adopts the formalization of project contracts with contractual clauses agreed between the parties involved in the cooperation, which can be renegotiated, and strengthens mutual trust between partners.

Project management $=03$ questions

48 - The organization adopts a systematic management methodology for technological innovation projects with defined tasks and roles. 
49 - The organization adopts a methodology for the systematic management of technological innovation projects with cooperation partners.

57 - The organization uses the techniques of integrated product design for technological innovation since the design of the project.

Research and development $=02$ questions

50 - The organization adopts computerized tools and systems for project management and monitoring as well as for interaction and engagement with cooperation partners.

51 - Our organization's laboratory infrastructure is sufficiently updated for its technological innovation purposes.

52 - The organization seeks cooperation in infrastructure for the design, construction and testing of prototypes, pilot installations, or software development that presents technological or scientific progress.

Technology transfer $=01$ question

53 - Our organization offers technical support for agreements for the acquisition and transfer of tangible and intangible technologies.

Information sources for innovation $=02$ questions

54 - The organization adopts tools and systems for identifying technological trends in support of R\&D projects.

55 - Our organization adopts practices of internal information collection regarding technological innovation in the areas of production, R\&D and engineering (technology push) and marketing (demand pull).

Financing and tax incentives for innovation=01 question

56 - The organization offers technical support for the identification and application of public funding and tax incentives for technological innovation projects.

Intellectual property $=02$ questions

58 - The complexity of intellectual property rights has an inhibiting effect on the propensity of the company and the research institution to get involved in cooperation projects for technological innovation.

59 - The organization strives to have clear rules on the appropriation of intellectual property since the mobilization for cooperation. 